\title{
NOWCASTING HOUSEHOLD CONSUMPTION AND INVESTMENT IN INDONESIA
}

\author{
Tarsidin, Idham, Robbi Nur Rakhman ${ }^{1}$
}

\begin{abstract}
It is imperative for the Central Bank to know the current state of the economy as the basis underlying projections of future economic conditions. To that end, current economic conditions, in this case household consumption and investment, could be predicted using nowcasting. In this research, a nowcasting model was developed for the two aforementioned macroeconomic variables using a Dynamic Factor Model (DFM). The indicators used when nowcasting household consumption included: motor vehicle sales, total deposits, the lending rate on consumer loans, M1, and the Rupiah Exchange Rate (NEER), while the indicators used for nowcasting investment included: cement sales, motor vehicle production, electric energy consumption, outstanding loans, and M1. Accuracy testing showed that the nowcasting model for household consumption using DFM was sound, while the forecast error for nowcasting investment was significant but remained below the benchmark.
\end{abstract}

Keywords: Nowcasting, Mixed Frequency Regression, Dynamic Factor Model JEL Classification: C38, C53

1. The authors would like to express appreciation to Yoga Affandi and Sahminan for their input, Ferry Kurniawan for his assistance and Prof. Dr. Abuzar Asra and authors' colleagues at the Economic and Monetary Policy Department (DKEM) for their input. The email addresses of the authors are as follows: tarsidin@bi.go.id, idham_a@bi.go.id, and robbi_nr@bi.go.id. The opinions expressed in this paper are those of the authors and do not necessarily represent the position or policy of Bank Indonesia. 


\section{INTRODUCTION}

According to the Forecasting and Policy Analysis (FPAS) framework, Bank Indonesia utilises the ARIMBI core model and several satellite models, such as SOFIE, MODBI, ISMA, and BIMA. The five models are fundamentally macroeconomic models used for short-term (up to two years) and medium-term (2-5 years) projections. In addition, Bank Indonesia also has several indicator models, including GDP, inflation and exchange rate models, which are used to produce near-term forecasts (for the current quarter and subsequent period) as well as nowcasting (current quarter).

Indicator models are crucial considering the importance of the Central Bank knowing the current state of the economy as the basis underlying projections of future economic conditions in line with international best practices at other central banks, including the Riksbanken and Bank of England. ${ }^{2}$ Furthermore, projections based on the indicator models are used as inputs for the macroeconomic models. Therefore, projections for the current quarter and subsequent period are fundamentally generated by the indicator models.

Considering the importance of indicator models, further development was required. Currently, Bank Indonesia only has indicator models for GDP, inflation, and the exchange rate but is lacking models for GDP components, such as consumption, investment, and exports/imports. This research developed an indicator model for nowcasting household consumption and investment. The model was expected to improve the accuracy of Bank Indonesia's economic projections and, therefore, support more precise monetary policymaking.

Nowcasting has developed rapidly over the past decade. The most commonly used methods include Bridge Equation, Mixed Data Sampling (MIDAS) developed by Ghysels, et al. (2004)), Mixed Frequency VAR (MF-VAR developed by Mariano and Murasawa (2010) as well as Schorfheide and Song (2013)) and the Dynamic Factor Model (DFM, otherwise known as the Mixed Frequency Factor Model (MFFM), developed by Mariano and Murasawa (2003) and Giannone, et al. (2008)).

Nowcasting GDP in Indonesia has been performed by Kurniawan (2014) using the MIDAS approach along with the Mixed Frequency Factor Model, as well as by Luciani, et al. (2015) using the Dynamic Factor Model. Nowcasting has been proven to effectively bolster economic assessments in Indonesia.

\section{THEORY}

Under the ITF framework, it is imperative that Bank Indonesia is constantly aware of the current state of the economy and how close the economy is to equilibrium as the basis underlying projections of future economic conditions. By knowing the state of the economy and projections of upcoming conditions, Bank Indonesia can determine the appropriate monetary policy response to adopt. Over the past decade, nowcasting has been developed to assess the current state of the economy.

2. As cited by Angelini, et al. (2008), Andersson and Reijer (2015) as well as Bell, et al. (2014) amongst others. 
The term nowcasting defines the projections of a macroeconomic variable, for instance GDP, for the current quarter using higher frequency data.

\subsection{Nowcasting for Economic Assessment}

Prior to the 1990s, economic assessments were primarily based on the economic index developed by Burns and Mitchell (1946). The (US) Conference Board and OECD further developed the economic index, which was fundamentally an estimation of the business cycle by extracting the cycles of various series, ${ }^{3}$ determining the turning points ${ }^{4}$, determining the indicators with similar dynamics as the reference series and regressing into a single index. The Coincident Economic Index developed by the Conference Board and OECD illustrated the current state of the economy using nonfarm payrolls, personal income (after transfers), the industrial production index, as well as manufacturing and trade sector sales.

Nonetheless, various innovative new approaches began to appear around 1990 to estimate the coincident economic index using econometric methods. One such approach was developed by Stock-Wilson (1989) using Maximum Likelihood Factor Analysis, which is considered a milestone in the development of nowcasting.

Nowcasting, which is a method to project the state of the economy, was developed around the start of the $21^{\text {st }}$ century. There are similarities between the coincident economic index and nowcasting, namely that both using highfrequency indicators to capture the dynamics of a reference series (for example GDP). The difference is that the coincident economic index is a composite of various indicators with similar dynamics as the reference series, while nowcasting is an estimation of the magnitude of the reference series using representative indicators. Unlike the coincident economic index, nowcasting not only estimates the direction of current economic conditions but also the magnitude. Seminal papers on nowcasting include Bridge Equation Mariano and Murasawa (2203), Ghysels, et al. (2004), Giannone, et al. (2008) and Doz, et al. (2011).

Bańbura, et al. (2012) suggested that ideally, a nowcasting model would formulate several major characteristics relating to market behaviours and institute policy referring to actual data in real-time. In relation to the nowcasting model, Bell, et al. (2014), applied two methods, namely the industry model and the weighted survey model. The industry model used industry-level data and a series of indicators for nowcasting GDP, while the weighted survey model merely relied on survey indicators (excluding formally published data).

There is now a range of literature that deals with nowcasting GDP for economic assessment. Nowcasting in the UK was conducted by Bell, et al. (2014), in the Euro area by Angelini, et al. (2008) and in Sweden by Andersson and Reijer (2015). Furthermore, nowcasting has also been performed in Indonesia by Kurniawan (2014) and Luciani, et al. (2015).

3. Using the Phase Average Trend (PAT) method, Hodrick-Prescott (HP) filter or Christiano-Fidgerald (CF) filter as per the OECD (2012).

4. Using the Bry-Boschan algorithm. 
In addition to nowcasting GDP, nowcasting other variables (such as inflation) as well as components of GDP (including household consumption and investment) has also been achieved but the literature remains limited. Nowcasting of GDP components was performed by Baffigi, et al. (2004), amongst others, who conducted nowcasting using the Bridge Equation Method. The results showed that the retail sales index is an important component of household consumption, while the Consumer Confidence Index (CCI) plays only a minor role (possibly due to correlation with other indicators). Motor vehicle registrations was another indicator with close correlation to the consumption of durable goods. On the other hand, however, survey data was found to represent a sound proxy of investment, particularly the short-term dynamics of demand along with construction.

Sørensen (2011) stated that considering the large contribution of household consumption to GDP, household consumption is an important factor when assessing the state of the economy. A simple regression (OLS) nowcasting method was used à la Bridge equation, where the indicator was selected using the generalto-specific approach based on information criteria, model reduction tests and misspecification tests. The salient indicators found by Sørensen (2011) included: new registrations of passenger vehicles, the velocity of money and the Consumer Confidence Index (CCI), while the retail sales index was not found to be significant.

\subsection{Nowcasting Method}

As mentioned previously, several nowcasting methods are commonly used, including Bridge Equation, Mixed Data Sampling (MIDAS), Mixed Frequency VAR, and Mixed Frequency Factor Model (often referred to as Dynamic Factor Model). The four methods are explored in the following section, as cited in Foroni and Marcellino (2013).

\section{1) Bridge Equation}

The Bridge Equation is a linear regression that correlates high-frequency variables (for instance monthly retail sales) with lower frequency variables (quarterly GDP for example), thereby producing an estimation of the latest economic conditions prior to the release of the quarterly data. This method was introduced by Baffigi, et al. (2004). The Bridge model can be expressed as the following equation:

$$
y_{t_{q}}=\alpha+\sum_{i=1}^{j} \beta_{i}(L) x_{i t_{q}}+u_{t_{q}}
$$

where:

$y_{t} \quad$ : reference series (quarterly)

$x_{t} \quad$ : monthly indicators aggregated to quarterly indicators

$\beta_{i}(L)$ : lag polynomial coefficients

The Bridge Equation is resolved through two stages as follows: (i) the monthly indicators are projected for the current quarter (for instance using ARIMA or VAR) 
and then aggregated to obtain a quarterly value; and (ii) the aggregated indicator value is set as the regressor. Bańbura, et al, (2012) found that the Bridge Equation only captured limited aspects of the nowcasting process, which is understandable considering the monthly indicators are aggregated into quarterly data, thus some of the latest information is lost.

\section{2) Mixed Data Sampling}

The aggregation process involved in the Bridge Equation, where monthly indicators are aggregated into quarterly data, has the potential to lose some of the important information from the data. To overcome that problem, an estimation method was developed based on mixed frequency data. Ghysels, et al. (2004) introduced a method known as Mixed Data Sampling (MIDAS). In this case, the dependent variable $y_{t}$ (representing lower-frequency, quarterly data) is regressed against a distributed lag of $x_{t}$ (representing higher-frequency, monthly data). The MIDAS equation can be specified as follows:

$$
y_{t_{m}}=\beta_{0}+\beta_{1} b\left(L_{m} ; \theta_{1}\right) x_{1, t_{m}+w-h_{m}}^{(m)}+\beta_{2} b\left(L_{m} ; \theta_{2}\right) x_{2, t_{m}+w-h_{m}}^{(m)}+\cdots+\varepsilon_{t_{m}}
$$

where:

$y_{t}$

$x_{t}$

$b\left(L^{1 / m} ; \theta\right)=\sum_{k=0}^{\mathrm{K}} c(k ; \theta) L_{m}^{k} \quad$ : lag polynomial coefficients

: reference series (quarterly)

: monthly indicators

The main characteristic of MIDAS is that the parameterisation of the lagged coefficients $\mathrm{c}(\mathrm{k} ; \theta)$ is modelled using the parsimonious distributed lag polynomials in order to avoid parameter proliferation that could emerge as well as issues related to the selection of the lag-order. In this case, parameterisation can be achieved using the exponential Almon lag, Beta lag, linear scheme, hyperbolic scheme, and geometric scheme.

Bańbura, et al. (2012) suggested that MIDAS represents an improvement on the Bridge Equation, which is understandable because MIDAS is fundamentally similar to the Bridge Equation. The only difference is that the temporal aggregation of mixed-frequency indicators is omitted. Nonetheless, MIDAS contains the problem of dimensionality and is limited in terms of the number of variables. A further review of MIDAS was conducted by Andreou, et al. (2010), who decomposed the MIDAS regression into two components, namely an aggregate component with the same weighting and a nonlinear component, and compared them to the Conventional Least Square Regression (temporal aggregation with the same weighting). The results showed that the MIDAS estimator is more efficient (robust).

\section{3) Mixed Frequency VAR}

Another common nowcasting approach is the Mixed Frequency VAR, for instance using a quarterly reference series and a monthly component series (indicators). By modelling the reference series and component series simultaneously, co- 
movement between the reference series and mixed frequency indicators can be analysed. Two Mixed Frequency VAR (MF-VAR) approaches are presented in the literature, namely the classical approach developed by Mariano and Murasawa (2010) as well as the Bayesian approach developed by Schorfheide and Song (2013). The MF-VAR equation can be express as follows:

$$
\emptyset\left(L_{m}\right)\left(\begin{array}{l}
y_{t_{m}}^{*}-\mu_{y}^{*} \\
x_{t_{m}}-\mu_{x}
\end{array}\right)=u_{t_{m}}
$$

where:

$y_{t_{m}}^{*} \quad$ : reference series (latent m-to-m growth)

$x_{t_{m}} \quad$ : monthly indicators

$L_{m}^{m} \quad$ : lag operator

\section{4) Mixed Frequency Dynamic Factor Model}

The Mixed Frequency Dynamic Factor Model is another common nowcasting approach. Using a factor model, the unobserved state of the economy is extracted and a new coincident indicator is constructed. More information is obtained using this approach and the projections estimated are more accurate. The methodology was developed from the Stock-Watson coincident index by Mariano and Murasawa (2003) for small-scale models and by Giannone, et al. (2008) for large-scale models. A detailed description of the methodology is presented in Bańbura, et al. (2011a).

Giannone, et al. (2008), as cited by Angelina, et al. (2008) and Foroni and Marcellino (2013), coined the approach, bridging with factors, considering the (quarterly) reference series is regressed with the (monthly) common factors as a form of bridging equation. As a preliminary step, the common factors are extracted from the monthly data series on a large scale using a two-step estimator. The model specification can be expressed as follows:

$$
\begin{array}{ll}
x_{t_{m}}=\Lambda f_{t_{m}}+\xi_{t_{m}} & \xi_{t_{m}} \sim N\left(0, \Sigma_{\xi}\right) \\
f_{t_{m}}=\sum_{i=1}^{p} A_{i} f_{t_{m}-i}+B \eta_{t_{m}} & \eta_{t_{m}} \sim N\left(0, \mathrm{I}_{q}\right)
\end{array}
$$

where:

$$
\begin{array}{ll}
x_{t_{m}} & : \text { monthly indicators } \\
f_{t_{m}} & : \text { common factors } \\
\Lambda & : \text { factor loadings } \\
\xi_{t_{m}} & : \text { idiosyncratic component }
\end{array}
$$

The monthly common factors are subsequently averaged. Time aggregation is applied by aligning the quarterly data with that of the third month in the respective quarter, while the first and second months data are calculated using the Kalman filter. ${ }^{5}$ The next stage involves projecting the reference series, for instance

5. For explanations on state space models and the Kalman filter refer to Hamilton (1994). 
the quarterly GDP series, based on the estimated common factors that have been regressed into quarterly data. The equation can be expressed as follows:

$$
\hat{y}_{t_{q}}=\alpha+\beta \hat{f}_{t_{q}}
$$

where:

$\hat{y}_{t_{q}} \quad$ : quarterly reference series

$\hat{f}_{t_{q}}$ : quarterly aggregated $\hat{f}_{t_{m}}$

Doz, et al. (2011) demonstrated consistency between the two-step estimator and maximum likelihood. In this case, the asymptotic properties were tested with various misspecifications. The results showed that the Factor Model with a maximum likelihood was robust to the misspecifications. Furthermore, Doz, et al. (2011) proposed two-step procedures to estimate the common factors when the model parameters are unknown. The first step is to calculate the preliminary estimators of the factors and estimators of the model parameters using Principal Component Analysis (PCA). The second stage involves calculating the heteroscedasticity of the idiosyncratic components and/or common factor dynamics. The actual values of the parameters are subsequently replaced with the estimations according to PCA and the factor dynamics are estimated from the preliminary estimates of the respective factors.

Bańbura and Rünstler (2011) developed the Factor Model by combining the model with the projection equation for quarterly GDP growth using the mixedfrequency approach similar to Mariano and Murasawa (2003) in order to include a static equation that linked the common factors $\left(f_{t}\right)$ with the latent variables in the form of monthly GDP growth $\left(\mathrm{y}_{\mathrm{t}}\right)$, which can be expressed as follows:

$$
y_{t}=\beta^{\prime} f_{t}+\varepsilon_{t} \quad \varepsilon_{t} \sim N\left(0, \sigma_{\varepsilon}^{2}\right)
$$

where:

$y_{t} \quad:$ reference series

$f_{t} \quad:$ common factors

$\varepsilon_{t} \quad:$ white noise error

The Dynamic Factor Model was subsequently developed further by Aruoba, et al. (2012) in order to use mixed-frequency and high-frequency data (including weekly, monthly and continuous data). As confirmed by Aruoba, et al. (2012), Stock and Wilson (1989) did not model the Factor Model with mixed-frequency and high-frequency data, while Mariano and Murasawa (2003) only modelled mixed-frequency data not high-frequency data.

Bańbura and Rünstler (2011) also developed the model by deriving the weighting of each indicator in the model, thereby revealing the actual contribution of each respective indicator to the projection. Meanwhile, Diebold and Rudebusch (1996) stressed the need for a regime switching synthesis in the Dynamic Factor Model and explored a framework to that end. In addition, the interplay between the reference series and its common factors should be observed, as modelled using 
Factor-Augmented Vector Autoregression (FAVAR) mentioned by Andersson and Reijer (2015).

\section{METHODOLOGY}

\subsection{Method}

Nowcasting using the Factor Model is commonly used by central banks to predict current quarter GDP, including the Riksbanken ${ }^{6}$, Norges Bank, European Central Bank (ECB) ${ }^{7}$, Bank Indonesia ${ }^{8}$, and by international organisations including $\mathrm{ADB}^{9}$. The capacity to accommodate numerous indicators ensures the popularity of the Factor Model. Nowcasting household consumption and investment is not dissimilar to nowcasting GDP. Therefore, the nowcasting method typically used for GDP can also be applied to nowcasting other lower-frequency variables (including household consumption and investment), as suggested by Bańbura, et al (2011b).

The preferred method in this research is the Mixed Frequency Dynamic Factor Model (abbreviated to DFM). There are a number of significant variations to the estimates and projections using DFM. In this research, the authors were inclined to follow the approach of Giannone, et al. (2008), developed by Bańbura and Rünstler (2011) and modified by Kurniawan (2014). The model specification can be expressed as follows:

$$
\begin{array}{ll}
z_{t}=\Lambda \beta_{t} & u_{t} \sim N\left(0, \Sigma_{u}\right) \\
\beta_{t}=F \beta_{t-1}+\varepsilon_{t} & \varepsilon_{t} \sim N\left(0, \sigma_{\varepsilon}^{2}\right)
\end{array}
$$

where:

$z_{t} \quad$ : consists of reference series $\left(y_{t}\right)$ and monthly indicators $\left(x_{t}\right)$

$f_{t} \quad$ : common factors

$\Lambda \quad$ : factor loadings

$u_{t} \quad$ : idiosyncratic component

$\beta_{t} \quad$ : consists of common factors $\left(f_{t}\right)$ and idiosyncratic component $\left(u_{t}\right)$

$F \quad$ : autoregressive coefficients

$\varepsilon_{t} \quad$ : white noise error

The state space in Equations 3.1 and 3.2 was built in the form of a matrix as follows:

6. Refer to Andersson and Reijer (2015).

7. Refer to Angelina, et al. (2008).

8. Refer to Kurniawan (2014).

9. Refer to Luciani, et al. (2015). 


\section{Measurement Equation:}

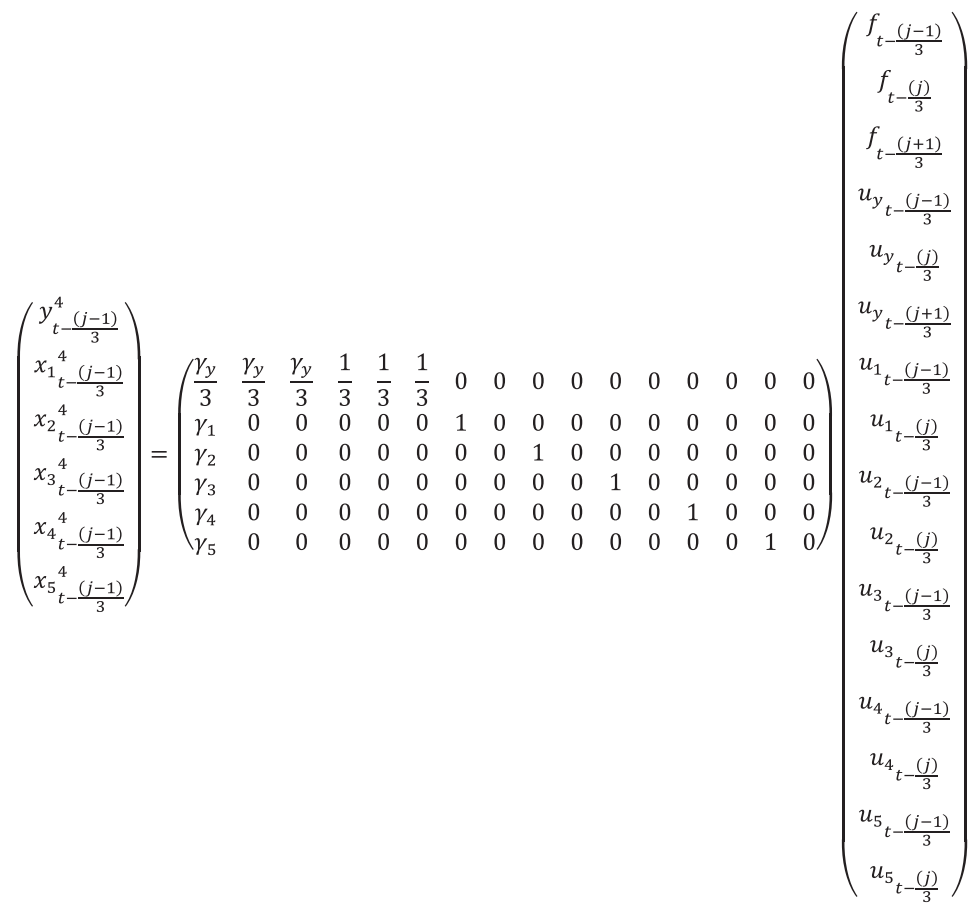

\section{Transition Equation:}

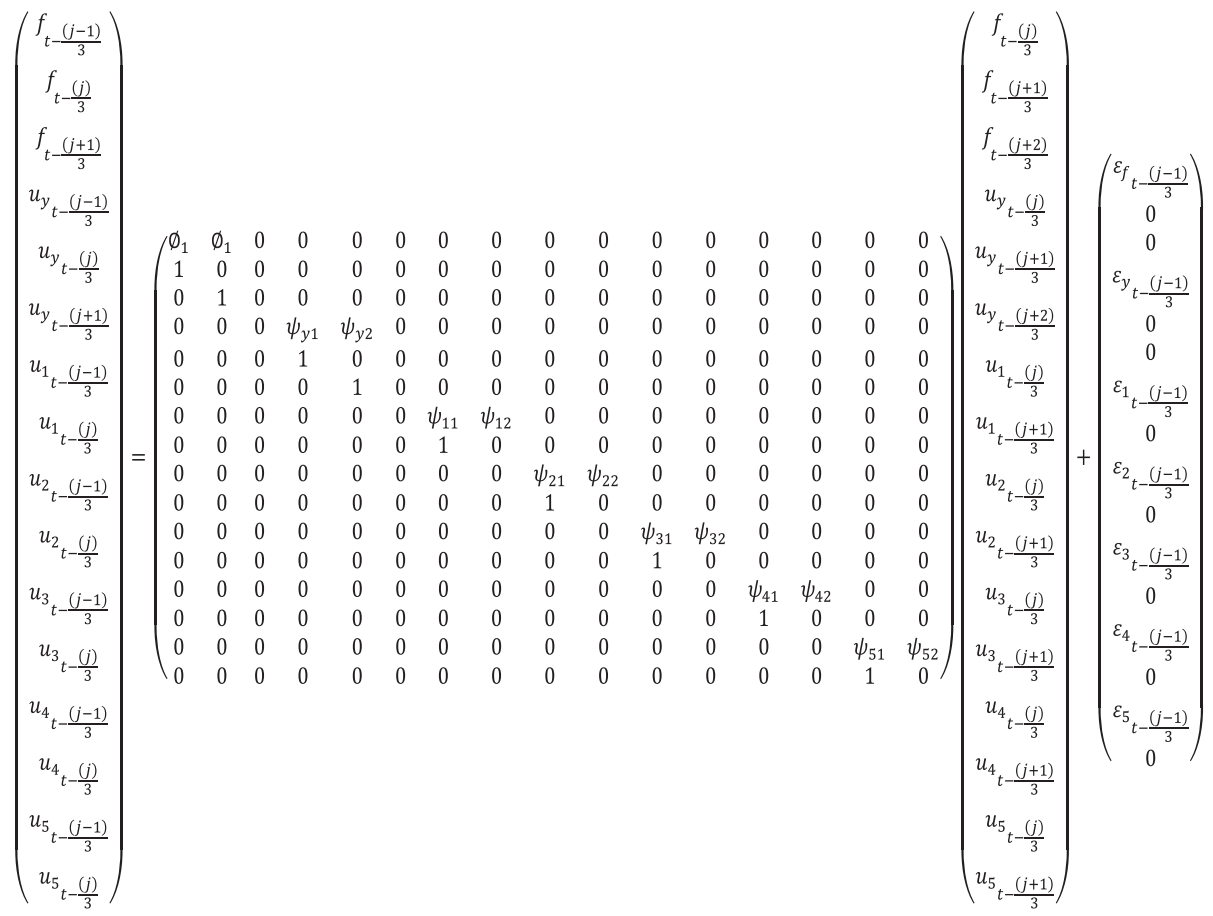


Equations 3.1 and 3.2 were estimated in two stages, known as the two-step estimator. The first stage involved estimating the representative parameters of the state space using the principal components (from the balanced panel of monthly indicators $\left.{ }^{10}\right)$, thus estimating the magnitude of the common factors. In the second stage, the common factors were re-estimated by applying a Kalman smoother to the entire information set. The reference series (household consumption and investment) was subsequently projected by regressing the latent variables in the form of year-on-year household consumption growth and year-on-year investment growth against the common factors.

\subsection{Data}

The data used in this research was for the period from 2003-2015. The estimations were based on data from 2003-2015 and the pseudo out-of-sample testing used 2015 data. The reference series were household consumption and investment, while the component series were various representative indicators selected from a range of candidate indicators. The reference series had a quarterly frequency and the data is published by BPS-Statistics Indonesia. Meanwhile, the indicators in the component series were mixed frequency, with the majority in the form of monthly data. Not all data for the indicators was available from 2003-2015. Therefore, the data was ragged data with differing availability across the period.

Since 2015, BPS-Statistics Indonesia has released data using 2010 as the base year for 2010-2015 data. Previous BPS data used 2000 as the base year. In a departure from the previous data, household consumption data using 2010 as the base year does not contain the consumption of non-profit institutions. Data with a base year of 2010 was applied in this research, therefore the data did not contain the consumption of non-profit institutions. For earlier years (2003-2009), however, backcasting was applied to the growth in order to obtain household consumption without the consumption of non-profit institutions. Similarly, for investment the data used had a base year of 2010, so for previous years backcasting was again applied.

The data was divisible into soft data and hard data, as suggested by Bańbura and Rünstler (2011) as well as Bańbura, et al. (2012). Soft data (such as survey data and financial data) is available before hard data (such as statistical data released by BPS-Statistics Indonesia). Hard data contains more reliable information. The representative indicators were also categorised as hard indicators and soft indicators, consistent with Angelina, et al. (2008). Hard indicators are released later than soft indicators but the data contained is more reliable. The contribution of soft data is large at the beginning of the quarter but small at the end and vice versa for hard data. Considering the different contributions, the two types of data were also assigned different weights. Bańbura and Rünstler (2011) stated that hard data (real activity data) is an invaluable source of information but when the late

10. As mentioned by Bańbura, et al. (2012), $x_{t}$ only contains observable monthly indicators, thus omitting quarterly series of household consumption and investment, as well as monthly latent series. 
publication is taken into account, hard data becomes less relevant. In this case, survey and financial data become more important.

\subsection{Stages}

The stages of nowcasting household consumption and investment involved: indicator selection, filtering and transformation, the nowcasting exercise, and model performance evaluation.

\section{1) Indicator Selection}

Although the modelling was not required to find causality between the component series and reference series, this does not imply that any indicator could be inputted to the model. The indicators should have a close relationship with their reference series, in this case household consumption and investment (PMTB). OECD (2012) found that their economic relevance must be considered when selecting the indicators (economically significant and a broad scope). In a different context (leading indicators, not coincident indicators), OECD (2012) stated that the indicators should meet one of the following criteria: early stage, rapidly responsive, expectation-sensitive or prime mover. Similar findings were put forward by Riksbanken, cited by Andersson and Reijer (2015), namely that the selected indicators should influence the business cycle, the variables should react at the beginning of the business cycle and the series should gauge the beginning of the production chain as well as the expectations of economic agents (typically collated from surveys).

In addition to economic relevance, a number of other requirements must also be met. OECD (2012) stressed the need for an indicator with a monthly frequency that is rarely revised, published on time and with a long data series. During the initial stage, several candidate indicators were selected that meet the requirements in terms of economic relevance and practical considerations. The candidate indicators were subsequently whittled down using several criteria in order to observe the correlation with the reference series (based on the coefficient of correlation) and similarity of the common factors with the reference series (based on Principal Component Analysis). Several indicators were thus selected for use in the estimations. In the literature, relatively large data sets were also used, exceeding 50 variables, arguing that each variable contains specific information about the economy that might be absent from the other variables.

\section{2) Filtering and Transformation}

Prior to use in the estimations, the data must be filtered using seasonal adjustments with X-12 or TRAMO/SEATS. More robust estimations are possible by omitting seasonal factors from the reference series and component series. Nonetheless, when the data was used for projections, the prediction was the actual value that contains seasonal factors. Therefore, the results must be multiplied or added to the seasonal factors for comparison with the realised data. 
Another common approach is to exclude the seasonal adjustment. Therefore, direct comparisons with the realised data are possible. This approach is appropriate if similar seasonal factors are found in the reference series and component series. The estimations may be compromised, however, if the seasonal factors are different in the reference series and component series, leading to less robust estimations. Considering that the data on household consumption and investment released by BPS-Statistics Indonesia has not had the seasonal factors removed, seasonal adjustments were preferred in this research.

The correlation between the reference series and component series (indicators) depends on whether the indicators are stock data or flow data, and how the indicators are transformed before being inputted into the model (for instance the stationarity requirements), as suggested by Bańbura, et al. (2012). Data may be presented in the form of level, percentage, index or unit. Level data was based on constant prices (real value). Data in level, index and unit were transformed into year-on-year growth. Percentage data, on the other hand, was transformed into the difference with the previous year. The reference series and indicators were then standardised for comparison.

\section{3) Nowcasting Exercise}

As mentioned previously, the estimations were made using the Dynamic Factor Model and data for the period from 2003-2015. In this case, a nowcasting exercise was conducted systematically using various combinations of component series, namely consisting of 4, 5, and 6 indicators from the range of candidate indicators selected. The best model was chosen based on pseudo out-of-sample testing of the data from 2015 to predict household consumption and investment in each quarter of the year. The model with the smallest RMSE was selected, demonstrating that the prediction model was more accurate.

A more rigorous test was conducted for the fourth quarter of 2015, namely weekly predictions for the first, second, and third months in line with data availability (released data). To that end, the approach of Camacho and PerezQuiros (2010) was used to evaluate the results of the nowcasting exercise by using real-time conditions and revised data. Consequently, a real-time dataset was built consisting of vintage data (historical data) available for each of the nowcasting data points.

To enhance the prediction capabilities, Giannone, et al. (2008) as well as Bańbura and Rünstler (2011) proposed uncertainty measures (that show the marginal gain on the prediction precision) to assess the role of latest data releases. Furthermore, Bańbura and Rünstler (2011) stressed the need for different weightings on each indicator in every prediction period. Therefore, when using the prediction model, different indicators could be used or even large datasets (consisting of timely indicators and/or indicators containing important information). 


\section{4) Model Performance Evaluation}

The next stage involves evaluating the performance of the selected model. The evaluation takes into account a comparison with the benchmark models, including the Bridge Equation and ARIMA model. A comparison with the Bridge Equation was chosen due to the simplicity of the model. Meanwhile, the ARIMA model is known for its near-term forecasting accuracy compared to naïve methods and other simple models.

\section{RESULTS AND ANALYSIS}

The following section explores the results of the indicator selection, data management as well as estimations and predictions using the Dynamic Factor Model (DFM). In this case, a number of models with several different combinations of indicators were estimated in order to produce a more robust nowcasting model.

\subsection{Indicator Selection}

As mentioned previously, there were two requirements of indicator selection, namely economic relevance and practical considerations. Based on those considerations, a number of candidate indicators were selected for household consumption and investment that met both requirements, at least to some extent. From there, a number of candidate indicators were subsequently selected in order to observe their coefficient of correlation and contribution to explain the reference series for potential use in the estimations.

\section{1) Indicators of Household Consumption}

Household consumption is the largest component of GDP. During the observation period from 2003-2015, household consumption accounted for 54$63 \%$ of GDP. A number of indicators were found to have a high coefficient of correlation to household consumption as follows:

- Indicators representing the magnitude of household consumption, including motor vehicle sales and the retail sales index;

- Indicators reflecting consumer opinion of economic conditions that underlie their consumption decisions, including the consumer confidence index (composite, current economic condition, and expectation) as well as consumer tendency index;

- Economic performance indicators, which ultimately impact the level of household income and consumption, including the industrial production index, export YTD, import YTD, loading/unloading of cargo (through domestic and international ports), and the stock price index at the Indonesia Stock Exchange; and

- Indicators related to banking, economic liquidity, and exchange rates, which influence consumers' consumption decisions, including total deposit, credit (consumer and total), 1, 3 and 6-month term deposit rates, the consumer lending rate, M1, M2 as well as the Rupiah exchange rate against the US dollar and the effective exchange rate, both nominal and real. 
Of the various candidate indicators mentioned, several indicators with the highest coefficient of correlation were selected. Table 1 presents the coefficients of correlation of several candidate indicators in terms of level and year-on-year growth (its difference for data in percentages) against household consumption. Indicators with a correlation coefficient value of 0.70 or more and a year-onyear growth correlation coefficient value of 0.15 or more as well as the correct correlation sign were selected for the evaluation stage.

Table 1.

Correlation Coefficients of Indicators of Household Consumption

\begin{tabular}{|c|c|c|c|}
\hline \multirow[b]{2}{*}{ No. } & \multirow[b]{2}{*}{ Indicators } & \multicolumn{2}{|c|}{ Correlation Coefficient } \\
\hline & & Level & $\begin{array}{l}\text { Growth y-o-y } \\
\text { (Its difference } \\
\text { for data in \%) }\end{array}$ \\
\hline 1 & Motor vehicle sales & 0.90 & 0.25 \\
\hline 2 & Retail sales index & 0.97 & 0.30 \\
\hline \multirow[t]{4}{*}{3} & Consumer confidence index: & & \\
\hline & CCI - composite & 0.83 & 0.13 \\
\hline & CCI - current economic condition & 0.89 & 0.19 \\
\hline & CCI - expectation & 0.69 & 0.09 \\
\hline 4 & Consumer tendency index & -0.24 & 0.00 \\
\hline 5 & Industrial production index & 0.96 & 0.18 \\
\hline 6 & Export YTD & 0.59 & -0.15 \\
\hline 7 & Import YTD & 0.36 & -0.11 \\
\hline \multirow[t]{5}{*}{8} & Loading/unloading of cargo: & & \\
\hline & Cargo loading in domestic ports & 0.74 & -0.34 \\
\hline & Cargo unloading in domestic ports & -0.28 & -0.17 \\
\hline & Cargo loading in international ports & -0.30 & -0.27 \\
\hline & Cargo unloading in international ports & 0.78 & -0.06 \\
\hline 9 & Stock price index at IDX & 0.97 & 0.19 \\
\hline 10 & Total deposit & 0.98 & 0.48 \\
\hline \multirow[t]{3}{*}{11} & Credit: & & \\
\hline & Consumption & 0.99 & 0.06 \\
\hline & Total & 0.99 & 0.37 \\
\hline \multirow[t]{4}{*}{12} & Deposit rate: & & \\
\hline & 1 month & -0.59 & -0.32 \\
\hline & 3 months & -0.60 & -0.32 \\
\hline & 6 months & -0.63 & -0.35 \\
\hline 13 & Consumer lending rate & -0.92 & -0.34 \\
\hline 14 & M1 & 0.98 & 0.41 \\
\hline 15 & M2 & 0.98 & 0.54 \\
\hline \multirow[t]{4}{*}{16} & Rupiah exchange rate: & & \\
\hline & Rupiah to USD & 0.65 & 0.09 \\
\hline & NEER & -0.91 & -0.19 \\
\hline & REER & 0.60 & -0.39 \\
\hline
\end{tabular}


Based on those criteria, the following indicators were selected: motor vehicle sales, retail sales index, consumer confidence index - current economic condition, industrial production index, stock price index at the Indonesia Stock Exchange, total deposit, credit, consumer lending rate, M1, M2, and Nominal Effective Exchange Rate (NEER). To reduce the potential number of indicator combinations, a number of indicators were discarded due to their close resemblance to other indicators (with a higher correlation coefficient).

A number of practical considerations are presented in Table 2. All indicators have a monthly frequency, no (significant) data revisions and a publication lag of 7 days to 3 months. Despite a publication lag of 2-3 months, the industrial production index was included due to the important information contained in the indicator. A lag of three months was rare, with two months the norm.

Table 2.

Practical Considerations of Indicators of Household Consumption

\begin{tabular}{llccc}
\hline No. & \multicolumn{1}{c}{ Indicators } & Frequency & $\begin{array}{c}\text { Data } \\
\text { Revision }\end{array}$ & $\begin{array}{c}\text { Publication } \\
\text { Lag }\end{array}$ \\
\hline 1 & Motor vehicle sales & Monthly & No & $7-15$ days \\
2 & Retail sales index & Monthly & $\begin{array}{c}\text { Yes, but not } \\
\text { significant }\end{array}$ & 7 days \\
3 & $\begin{array}{l}\text { Consumer confidence index } \\
\text { - current economic condition }\end{array}$ & Monthly & No & 9 days \\
4 & Industrial production index & Monthly & Yes, but not & $2-3$ months \\
& significant & \\
5 & Stock price index at IDX & Monthly & No & 1 day \\
6 & Total deposit & Monthly & No & 2 months \\
7 & Total credit & Monthly & No & 2 months \\
8 & Consumer lending rate & Monthly & No & 2 months \\
9 & M1 & Monthly & Yes, but not & 2 months \\
& & significant & \\
10 & M2 & Monthly & Yes, but not & 2 months \\
& & significant & \\
11 & Rupiah exchange rate (NEER) & Monthly & No & 1 month \\
\hline
\end{tabular}

The candidate indicators selected based on the correlation of coefficient were subsequently analysed using Principal Component Analysis (PCA) to identify similarities between the common factors and household consumption. The results are presented in Figure 4.1, where component 1 contributed 34.70\%, component 2 contributed $18.50 \%$, and component 3 contributed $15.80 \%$ (with the three components explaining nearly $70 \%$ in total). No evidence was found of certain indicators having an extremely close correlation with household consumption. Therefore, the 11 indicators were used in the DFM estimation. 
Figure 1.

Principal Component Analysis of Indicators of Household Consumption
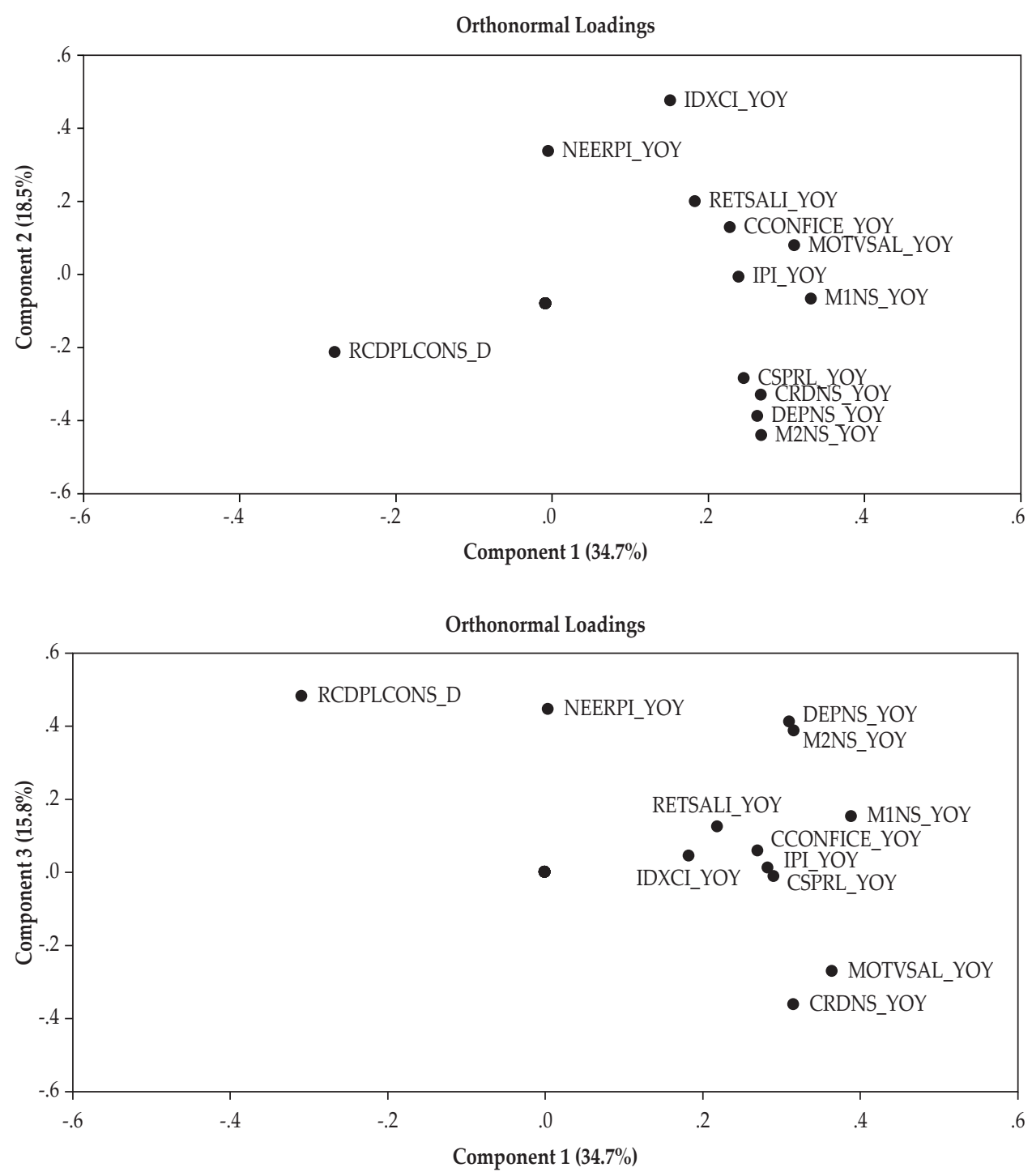

\section{2) Indicators for Investment}

Investment, or Gross Fixed Capital Formation (GFCF), is also a significant component of GDP. Although the contribution to GDP is not massive, in the range of $25-35 \%$ during the observation period of 2003-2015, investment plays a salient role in an economy. Investment consists of construction and non-construction investment (including machinery and equipment, vehicles, other equipment, cultivated biological resources, and intellectual property products). Several indicators correlate closely with investment, which can be categorised as follows: 
- Indicators representing the size of investment, including capital spending (state budget), cement sales, and motor vehicle production;

- Indicators reflecting corporate and household expectations of economic conditions, which underlie their investment decisions, including the consumer confidence index (composite, current economic condition, and expectation), selling prices (realization and expectation) as well as usage of labor (realization and expectation);

- Indicators of corporate conditions, which indicate corporate ability to invest, including corporate financial conditions and access to credit;

- Economic performance indicators, which ultimately influence corporate and household ability to invest, including the industrial production index, production capacity utilization, electricity consumption, export YTD, import YTD, loading/unloading of cargo (through domestic and international ports), market capitalization and stock price index at the Indonesia Stock Exchange; and

- Indicators related to banking, economic liquidity, and exchange rates, which influence corporate and household investment decisions, including credit (working capital, investment, and total), lending rates (working capital and investment), M1, M2 as well as the Rupiah exchange rate against the US dollar and the effective exchange rate, both nominal and real.

Several indicators with the highest coefficient of correlation were selected from the various candidates. Table 3 presents the coefficients of correlation of several candidate indicators in terms of level and year-on-year growth (its difference for data in percentages) against investment. Indicators with a correlation coefficient value of 0.70 or more and a year-on-year growth correlation coefficient value of 0.15 or more as well as the correct correlation sign were selected for the evaluation stage.

Table 3.

Correlation Coefficients of Indicators of Investment

\begin{tabular}{llcc}
\hline \multicolumn{1}{c}{ Indicators } & \multicolumn{2}{c}{ Correlation Coefficient } \\
\cline { 3 - 4 } No. & & Level & $\begin{array}{c}\text { Growth y-o-y } \\
\text { (Its difference } \\
\text { for data in \%) }\end{array}$ \\
\hline 1 & Capital spending (state budget) & 0.36 & -0.10 \\
2 & Cement sales & 0.86 & 0.18 \\
3 & Motor vehicle production & 0.91 & 0.47 \\
4 & Consumer confidence index: & & \\
& CCI - composite & 0.84 & 0.18 \\
& CCI - current economic condition & 0.90 & 0.22 \\
& CCI - expectation & 0.70 & 0.14 \\
5 & Business tendency index & -0.26 & 0.14 \\
6 & Business activity: & & \\
& Realization & 0.16 & 0.12 \\
& Expectation & 0.03 & 0.09 \\
\hline
\end{tabular}


Table 3.

Correlation Coefficients of Indicators of Investment - Continued

\begin{tabular}{|c|c|c|c|}
\hline \multirow[b]{2}{*}{ No. } & \multirow[b]{2}{*}{ Indicators } & \multicolumn{2}{|c|}{ Correlation Coefficient } \\
\hline & & Level & $\begin{array}{l}\text { Growth y-0-y } \\
\text { (Its difference } \\
\text { for data in \%) }\end{array}$ \\
\hline \multirow[t]{3}{*}{7} & Selling prices: & & \\
\hline & Realization & 0.21 & 0.07 \\
\hline & Expectation & 0.03 & 0.37 \\
\hline \multirow[t]{3}{*}{8} & Usage of labor: & & \\
\hline & Realization & 0.01 & 0.04 \\
\hline & Expectation & 0.17 & -0.04 \\
\hline 9 & Financial condition & 0.51 & 0.23 \\
\hline 10 & Access to credit & 0.72 & -0.09 \\
\hline 11 & Industrial production index & 0.95 & 0.26 \\
\hline 12 & Production capacity utilization & 0.66 & 0.09 \\
\hline 13 & Electricity consumption & 0.98 & 0.24 \\
\hline 14 & Export YTD & 0.63 & 0.32 \\
\hline 15 & Import YTD & 0.47 & 0.50 \\
\hline \multirow[t]{5}{*}{16} & Loading/unloading of cargo: & & \\
\hline & Cargo loading in domestic ports & 0.76 & 0.00 \\
\hline & Cargo unloading in domestic ports & -0.26 & 0.17 \\
\hline & Cargo loading in international ports & -0.28 & 0.16 \\
\hline & Cargo unloading in international ports & 0.79 & 0.10 \\
\hline 17 & Market capitalization & 0.96 & 0.13 \\
\hline 18 & Stock price index at IDX & 0.97 & 0.09 \\
\hline \multirow[t]{4}{*}{19} & Credit: & & \\
\hline & Working capital & 0.98 & 0.62 \\
\hline & Investment & 0.95 & 0.30 \\
\hline & Total & 0.98 & 0.71 \\
\hline \multirow[t]{3}{*}{20} & Lending rate: & & \\
\hline & Working capital & -0.84 & -0.49 \\
\hline & Investment & -0.89 & -0.54 \\
\hline 21 & M1 & 0.99 & 0.42 \\
\hline 22 & M2 & 0.97 & 0.16 \\
\hline \multirow[t]{4}{*}{23} & Rupiah exchange rate: & & \\
\hline & Rupiah to USD & 0.62 & 0.23 \\
\hline & NEER & -0.91 & -0.41 \\
\hline & REER & 0.60 & -0.50 \\
\hline
\end{tabular}

Based on those criteria, the following indicators were selected: cement sales, motor vehicle production, the consumer confidence index - state of the economy, industrial production index, electricity consumption, export YTD, import YTD, credit (working capital, investment and total), lending rates (working capital and investment), M1 and the Nominal Effective Exchange Rate (NEER). To reduce the potential number of indicator combinations, a number of indicators 
were discarded due to their close resemblance to other indicators (with a higher correlation coefficient), namely the consumer confidence index - composite was represented by the consumer confidence index - current economic condition, which is also considered more accurate for nowcasting of investment in the current quarter; working capital credit and investment credit were also omitted because they are represented by total credit, the lending rate on working capital was represented by the lending rate on investment and M2 was represented by M1. Meanwhile, the indicators of export YTD and import YTD were selected because of a high correlation coefficient value in terms of year-on-year growth and, from the perspective of economic relevance, a close correlation with investment despite a correlation coefficient of less than 0.70 .

A number of practical considerations are presented in Table 4. All indicators are shown to have a monthly frequency, no (significant) data revisions and a publication lag of 7 days to 3 months. Similar to the household consumption nowcasting model, despite a publication lag of 2-3 months, the industrial production index was included.

Table 4.

Practical Considerations of Indicators of Investment

\begin{tabular}{llccc}
\hline No. & \multicolumn{1}{c}{ Indicators } & Frequency & $\begin{array}{c}\text { Data } \\
\text { Revision }\end{array}$ & $\begin{array}{c}\text { Publication } \\
\text { Lag }\end{array}$ \\
\hline 1 & Cement sales & Monthly & No & $11-15$ days \\
2 & Motor vehicle production & Monthly & No & $7-15$ days \\
3 & $\begin{array}{l}\text { Consumer confidence index } \\
\text { - current economic condition }\end{array}$ & Monthly & No & 9 days \\
4 & Industrial production index & Monthly & Yes, but not & $2-3$ months \\
& significant \\
5 & Electricity consumption & Monthly & No & 45 days \\
6 & Export YTD & Monthly & Yes, but not & 1 month \\
& significant & \\
7 & Import YTD & Monthly & Yes, but not \\
& & significant & 1 month \\
8 & Total credit & Monthly & No & 2 months \\
9 & Investment lending rate & Monthly & No & 2 months \\
10 & M1 & Monthly & Yes, but not & 2 months \\
& & significant & \\
11 & Rupiah exchange rate (NEER) & Monthly & No & 1 month \\
\hline
\end{tabular}

The candidate indicators were subsequently analysed using Principal Component Analysis (PCA) to identify similarities between the common factors and household consumption. The results are presented in Figure 4.2, where component 1 contributed $41.30 \%$, component 2 contributed $21.50 \%$, and component 3 contributed $9.10 \%$ (with the three components explaining nearly $70 \%$ in total). 
No evidence was found of certain indicators having an extremely close correlation with investment. Therefore, the 14 indicators were used in the DFM estimation.

Figure 2.

Principal Component Analysis of Indicators of Investment
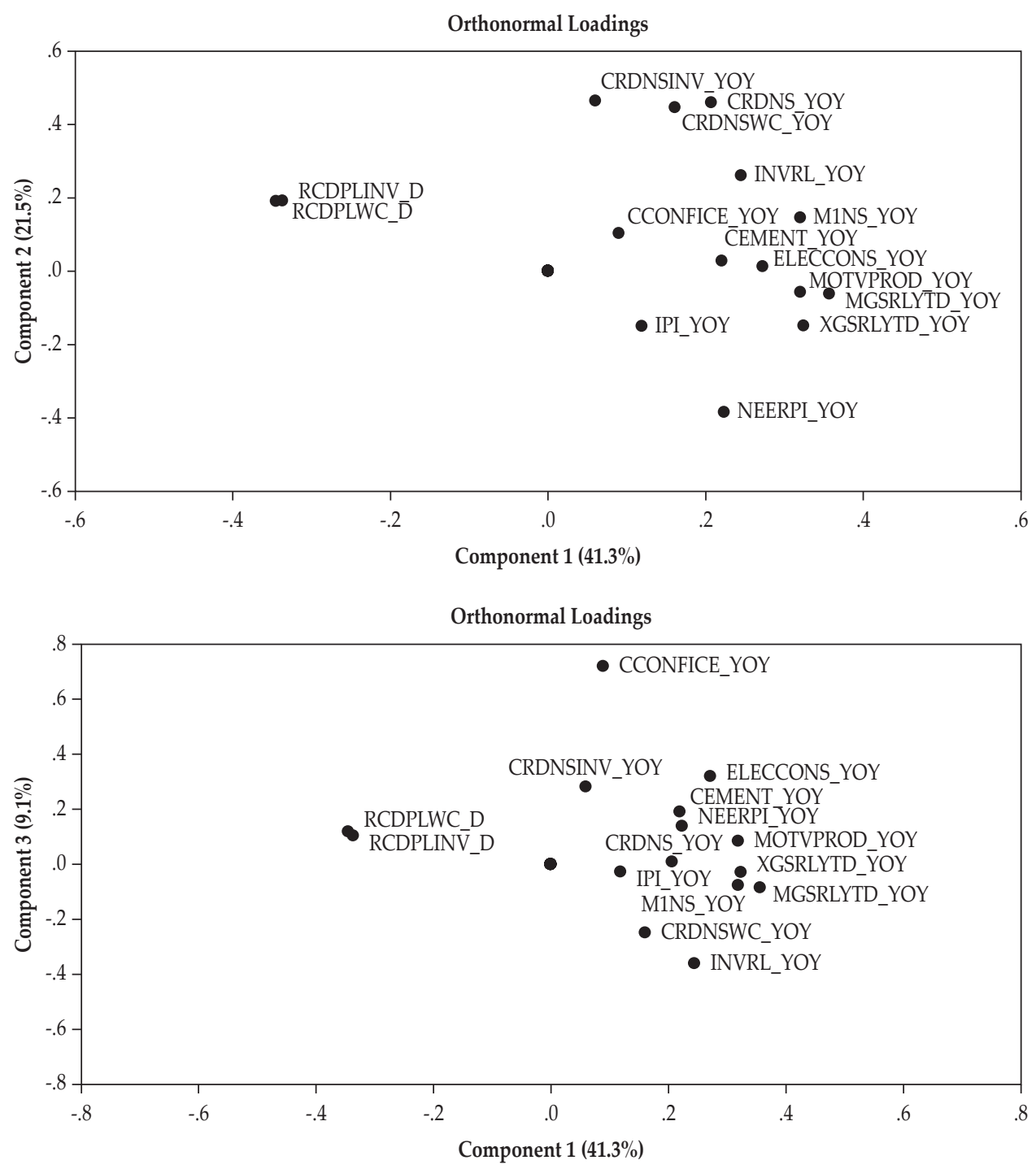

\subsection{Nowcasting Exercise}

An exercise was performed using various different combinations of indicators to obtain the best nowcasting model. Based on the results of pseudo out-ofsample testing, the model with the smallest RMSE was selected. What follows is a breakdown of the results: 


\section{1) Household Consumption}

Through the exercise, several combinations of the 11 selected indicators were tested, including 330 combinations of four indicators, 462 combinations of five indicators and 462 combinations of six indicators. The results of the ten best indicator combinations in the first, second, and third months are presented in Table 5. The exercise produced a component series of the best indicators, namely motor vehicle sales, total deposit, the consumer lending rate, M1 and the Rupiah exchange rate (NEER). Based on the RMSE, in the first month, the performance of the best combination of indicators was no more robust than several other combinations of indicators, but in the second and third months that combination ranked in first place.

Table 5.

Nowcasting Exercise - Household Consumption

\begin{tabular}{|c|c|c|c|c|c|c|}
\hline \multirow{3}{*}{ No. } & \multirow{3}{*}{$\begin{array}{l}\text { Component Series } \\
\text { (Indicators) }\end{array}$} & \multirow{2}{*}{\multicolumn{4}{|c|}{$\begin{array}{c}\text { Error } \\
\text { (Deviation of Nowcasting Result to Realization) } \\
2015 \\
\end{array}$}} & \multirow{3}{*}{ RMSE } \\
\hline & & & & & & \\
\hline & & I & II & III & IV & \\
\hline & $1^{\text {st }}$ month & & & & & \\
\hline 1 & F-G-H-I-K & $(0.01)$ & $(0.01)$ & 0.03 & 0.03 & 0.02 \\
\hline 2 & G-H-I-J-K & $(0.01)$ & $(0.01)$ & 0.03 & 0.03 & 0.02 \\
\hline 3 & F-G-I-J-K & $(0.01)$ & $(0.00)$ & 0.04 & 0.03 & 0.02 \\
\hline 4 & F-G-H-I-J & $(0.02)$ & $(0.01)$ & 0.04 & 0.03 & 0.03 \\
\hline 5 & A-F-H-I-K & $(0.01)$ & $(0.00)$ & 0.05 & 0.01 & 0.03 \\
\hline 6 & A-F-G-I-K & $(0.01)$ & 0.00 & 0.06 & 0.02 & 0.03 \\
\hline 7 & C-E-H-J-K & $(0.05)$ & $(0.01)$ & 0.02 & 0.02 & 0.03 \\
\hline 8 & C-E-G-H-K & $(0.05)$ & $(0.01)$ & 0.02 & 0.02 & 0.03 \\
\hline 9 & A-F-G-H-I & $(0.02)$ & $(0.00)$ & 0.05 & 0.01 & 0.03 \\
\hline \multirow[t]{2}{*}{10} & A-G-H-I-J & $(0.02)$ & $(0.01)$ & 0.05 & 0.01 & 0.03 \\
\hline & $2^{\text {nd }}$ month & & & & & \\
\hline 1 & A-F-H-I-K & 0.00 & 0.01 & 0.02 & 0.01 & 0.01 \\
\hline 2 & A-F-G-H-I & $(0.01)$ & 0.01 & 0.02 & 0.01 & 0.01 \\
\hline 3 & A-F-H-I-J & $(0.01)$ & 0.01 & 0.02 & 0.01 & 0.01 \\
\hline 4 & A-G-H-I-J & $(0.01)$ & 0.00 & 0.02 & 0.01 & 0.01 \\
\hline 5 & A-F-G-I-K & 0.00 & 0.01 & 0.02 & 0.01 & 0.01 \\
\hline 6 & A-F-G-I-J & $(0.01)$ & 0.01 & 0.02 & 0.01 & 0.02 \\
\hline 7 & A-C-H-I-K & 0.00 & 0.01 & 0.03 & 0.02 & 0.02 \\
\hline 8 & A-C-F-H-I & $(0.01)$ & 0.02 & 0.03 & 0.02 & 0.02 \\
\hline 9 & A-C-G-H-I & $(0.01)$ & 0.01 & 0.03 & 0.02 & 0.02 \\
\hline \multirow[t]{2}{*}{10} & A-E-H-I-K & $(0.01)$ & 0.01 & 0.03 & 0.02 & 0.02 \\
\hline & $3^{\text {rd }}$ month & & & & & \\
\hline 1 & A-F-H-I-K & $(0.01)$ & 0.03 & 0.01 & 0.01 & 0.02 \\
\hline 2 & A-F-H-I-J & (0.02) & 0.02 & 0.02 & 0.01 & 0.02 \\
\hline 3 & A-F-G-H-I & $(0.02)$ & 0.02 & 0.02 & 0.01 & 0.02 \\
\hline
\end{tabular}


Table 5.

Nowcasting Exercise - Household Consumption - Continued

\begin{tabular}{|c|c|c|c|c|c|c|c|}
\hline \multirow{3}{*}{ No. } & \multirow{3}{*}{$\begin{array}{l}\text { Component Series } \\
\text { (Indicators) }\end{array}$} & \multirow{2}{*}{\multicolumn{5}{|c|}{$\begin{array}{c}\text { Error } \\
\text { (Deviation of Nowcasting Result to Realization) } \\
2015\end{array}$}} & \multirow{3}{*}{ RMSE } \\
\hline & & & & & & & \\
\hline & & I & & II & III & IV & \\
\hline 4 & A-F-G-I-K & $(0.01)$ & & 0.03 & 0.02 & 0.02 & 0.02 \\
\hline 5 & A-G-H-I-J & $(0.02)$ & & 0.02 & 0.02 & 0.02 & 0.02 \\
\hline 6 & A-F-G-I-J & $(0.02)$ & & 0.02 & 0.02 & 0.02 & 0.02 \\
\hline 7 & D-E-I-J-K & $(0.01)$ & & 0.02 & 0.03 & 0.03 & 0.02 \\
\hline 8 & F-G-H-I-K & $(0.02)$ & & 0.01 & 0.02 & 0.03 & 0.02 \\
\hline 9 & F-G-I-J-K & $(0.02)$ & & 0.01 & 0.02 & 0.04 & 0.02 \\
\hline 10 & G-H-I-J-K & $(0.02)$ & & 0.01 & 0.02 & 0.04 & 0.02 \\
\hline \multicolumn{8}{|l|}{ Note: } \\
\hline \multicolumn{2}{|c|}{ Motor vehicle sales } & \multicolumn{5}{|c|}{ F Total deposit } & \\
\hline B $\mathrm{F}$ & Retail sales index & \multicolumn{2}{|r|}{ G } & \multicolumn{3}{|c|}{ Total credit } & \\
\hline \multirow[t]{2}{*}{ C } & Consumer confidence index & & $\mathrm{H}$ & \multicolumn{3}{|c|}{ Consumer lending rate } & \\
\hline & - current economic condition & & I & \multicolumn{3}{|c|}{ M1 } & \\
\hline D $\quad \mathrm{I}$ & Industrial production index & & $\mathrm{J}$ & \multicolumn{3}{|l|}{ M2 } & \\
\hline $\mathrm{E} S$ & Stock price index at IDX & & K & \multicolumn{3}{|c|}{ Rupiah exchange rate (NEER) } & \\
\hline
\end{tabular}

The selection of the best combination showed that the five aforementioned indicators had the highest resemblance of common factors to household consumption. Nonetheless, the results of the exercise presented in Table 5 also demonstrate that the difference in performance amongst the 10 best indicator combinations was almost negligible, evidenced by the small difference in RMSE. Therefore, a number of other indicators were also shown to be sufficiently robust for nowcasting household consumption.

Table 6 presents the results of nowcasting household consumption with the model selected for 2015, with an RMSE value of 0.02 and MAPE of $0.29 \%$ (based on the evaluation in the third month). Nowcasting was performed for each quarter of 2015 and the exercise showed that the nowcasting model was adequately robust from the first month, with no significant gains in accuracy found in the subsequent months. In fact, the results in the third month of the second quarter were no more accurate than the previous month.

Table 6.

Nowcasting with Selected Model - Household Consumption

\begin{tabular}{ccccccccc}
\hline \multirow{2}{*}{ Period } & \multirow{2}{*}{ Realization } & \multicolumn{3}{c}{ Nowcasting Result [and Error/Deviation] } \\
\cline { 4 - 9 } & & & \multicolumn{2}{c}{$\mathbf{1}^{\text {st }}$ month } & \multicolumn{2}{c}{$\mathbf{2}^{\text {nd }}$ month } & \multicolumn{2}{c}{$\mathbf{3}^{\text {rd }}$ month } \\
\hline \multirow{3}{*}{2015} & I & 5.01 & 5.00 & -0.01 & 5.01 & 0.00 & 5.00 & -0.01 \\
& II & 4.97 & 4.96 & 0.00 & 4.97 & 0.01 & 4.99 & 0.03 \\
& III & 4.95 & 5.00 & 0.05 & 4.97 & 0.02 & 4.96 & 0.01 \\
& IV & 4.92 & 4.93 & 0.01 & 4.93 & 0.01 & 4.94 & 0.01 \\
\hline
\end{tabular}


Table 7 presents the results of nowcasting household consumption in Q3-2015 using the latest data to represent actual conditions. The deviation was observed to increase to 0.05 in the first month in line with the inclusion of motor vehicle sales data. The deviation subsequently dropped significantly in the second month with the inclusion of the latest motor vehicle sales data. Furthermore, inclusion of the latest NEER data, total deposits, consumer loan interest rate and M1 in the third month, however, improved the nowcasting results.

Table 7.

Nowcasting Result Based on Data Flow (Q3-2015) - Household Consumption

\begin{tabular}{|c|c|c|c|c|c|}
\hline \multicolumn{2}{|c|}{ Period } & \multirow{2}{*}{ Data Release } & \multirow{2}{*}{\multicolumn{2}{|c|}{$\begin{array}{l}\text { Nowcasting Result } \\
\text { [and Error/ } \\
\text { Deviation] } \\
\end{array}$}} & \multirow{2}{*}{ Realization } \\
\hline Month & Week & & & & \\
\hline \multirow{4}{*}{$1^{\text {st }}$ month } & 1 & Rupiah exchange rate (NEER) & 4.98 & 0.03 & \multirow{12}{*}{4.95} \\
\hline & 2 & -- & 4.98 & 0.03 & \\
\hline & 3 & Motor vehicle sales & 5.00 & 0.05 & \\
\hline & 4 & $\begin{array}{l}\text { Total deposit } \\
\text { Consumer lending rate } \\
\text { M1 }\end{array}$ & 5.00 & 0.05 & \\
\hline \multirow{4}{*}{$2^{\text {nd }}$ month } & 1 & Rupiah exchange rate (NEER) & 5.00 & 0.05 & \\
\hline & 2 & -- & 5.00 & 0.05 & \\
\hline & 3 & Motor vehicle sales & 4.97 & 0.02 & \\
\hline & 4 & $\begin{array}{l}\text { Total deposit } \\
\text { Consumer lending rate } \\
\text { M1 }\end{array}$ & 4.97 & 0.02 & \\
\hline \multirow{4}{*}{$3^{\text {rd }}$ month } & 1 & Rupiah exchange rate (NEER) & 4.97 & 0.01 & \\
\hline & 2 & -- & 4.97 & 0.01 & \\
\hline & 3 & Motor vehicle sales & 4.97 & 0.02 & \\
\hline & 4 & $\begin{array}{l}\text { Total deposit } \\
\text { Consumer lending rate } \\
\text { M1 }\end{array}$ & 4.96 & 0.01 & \\
\hline
\end{tabular}

\section{2) Investment}

Similar to household consumption, several combinations of the 11 selected indicators were tested in the exercise. In total, 1,254 combinations were tested, consisting of 330 combinations of four indicators, 462 combinations of five indicators and 462 combinations of six indicators. The results of the ten best indicator combinations in the first, second and third months are presented in Table 8 . The exercise produced a component series of the best indicators, namely cement sales, motor vehicle production, electric consumption, outstanding loans, and M1. Based on the RMSE, the performance of the best combination of indicators ranked second in the first month but ranked first in the second and third months, while performing best in the second month when the RSME value was smallest. 
Table 8.

Nowcasting Exercise - Investment

\begin{tabular}{|c|c|c|c|c|c|c|c|}
\hline \multirow{3}{*}{ No. } & \multirow{3}{*}{$\begin{array}{l}\text { Component Series } \\
\text { (Indicators) }\end{array}$} & \multirow{2}{*}{\multicolumn{5}{|c|}{$\begin{array}{c}\text { Error } \\
\text { (Deviation of Nowcasting Result to Realization) } \\
2015\end{array}$}} & \multirow{3}{*}{ RMSE } \\
\hline & & & & & & & \\
\hline & & I & & II & III & IV & \\
\hline & $1^{\text {st }}$ month & & & & & & \\
\hline 1 & A-B-E-H-K & 0.79 & & 1.28 & $(0.43)$ & $(1.61)$ & 1.12 \\
\hline 2 & A-B-E-H-J & 0.82 & & 1.36 & $(0.46)$ & $(1.56)$ & 1.14 \\
\hline 3 & A-B-E-G-H & 0.81 & & 1.21 & $(0.53)$ & $(1.67)$ & 1.14 \\
\hline 4 & A-B-E-H-I & 0.90 & & 1.33 & $(0.40)$ & $(1.58)$ & 1.14 \\
\hline 5 & A-B-E-J-K & 0.87 & & 1.41 & $(0.39)$ & $(1.54)$ & 1.15 \\
\hline 6 & A-B-E-F-K & 0.90 & & 1.30 & $(0.43)$ & (1.63) & 1.16 \\
\hline 7 & A-B-G-H-K & 0.87 & & 1.43 & $(0.27)$ & (1.58) & 1.16 \\
\hline 8 & A-B-F-H-K & 0.91 & & 1.46 & $(0.24)$ & (1.57) & 1.17 \\
\hline 9 & B-E-G-H-K & 0.82 & & 1.40 & $(0.23)$ & $(1.68)$ & 1.17 \\
\hline \multirow[t]{2}{*}{10} & A-B-H-J-K & 0.89 & & 1.57 & $(0.20)$ & $(1.48)$ & 1.17 \\
\hline & $2^{\text {nd }}$ month & & & & & & \\
\hline 1 & A-B-E-H-J & 0.56 & & 0.97 & $(0.15)$ & $(1.62)$ & 0.99 \\
\hline 2 & A-B-E-H-K & 0.52 & & 1.01 & $(0.17)$ & (1.63) & 1.00 \\
\hline 3 & A-B-E-G-H & 0.49 & & 0.89 & $(0.27)$ & $(1.70)$ & 1.00 \\
\hline 4 & A-B-E-H-I & 0.61 & & 1.04 & $(0.13)$ & $(1.61)$ & 1.01 \\
\hline 5 & A-B-E-J-K & 0.62 & & 1.08 & $(0.05)$ & (1.58) & 1.01 \\
\hline 6 & A-B-E-F-J & 0.64 & & 0.99 & $(0.13)$ & $(1.64)$ & 1.01 \\
\hline 7 & A-B-E-G-J & 0.64 & & 0.97 & $(0.20)$ & (1.65) & 1.01 \\
\hline 8 & A-B-E-F-K & 0.57 & & 1.04 & $(0.14)$ & (1.65) & 1.02 \\
\hline 9 & A-B-E-F-G & 0.55 & & 0.90 & $(0.26)$ & (1.73) & 1.02 \\
\hline \multirow[t]{2}{*}{10} & A-B-E-I-J & 0.74 & & 1.11 & $(0.01)$ & $(1.55)$ & 1.02 \\
\hline & $3^{\text {rd }}$ month & & & & & & \\
\hline 1 & A-B-E-H-J & 0.48 & & 0.75 & (0.19) & $(1.84)$ & 1.03 \\
\hline 2 & A-B-E-J-K & 0.56 & & 0.85 & $(0.07)$ & $(1.81)$ & 1.04 \\
\hline 3 & A-B-E-H-K & 0.44 & & 0.80 & $(0.21)$ & $(1.86)$ & 1.04 \\
\hline 4 & A-B-E-H-I & 0.49 & & 0.87 & $(0.20)$ & $(1.84)$ & 1.05 \\
\hline 5 & A-B-E-I-J & 0.64 & & 0.91 & $(0.07)$ & $(1.79)$ & 1.05 \\
\hline 6 & A-B-E-F-J & 0.53 & & 0.78 & $(0.20)$ & $(1.88)$ & 1.06 \\
\hline 7 & A-B-E-G-J & 0.53 & & 0.74 & $(0.27)$ & $(1.90)$ & 1.06 \\
\hline 8 & A-B-E-G-H & 0.37 & & 0.71 & $(0.36)$ & $(1.95)$ & 1.07 \\
\hline 9 & A-B-E-F-K & 0.47 & & 0.85 & $(0.21)$ & $(1.90)$ & 1.07 \\
\hline 10 & A-D-E-G-J & 0.66 & & 0.97 & $(0.16)$ & $(1.80)$ & 1.08 \\
\hline \multicolumn{8}{|c|}{ Note: } \\
\hline \multicolumn{3}{|c|}{ Cement sales } & $\mathrm{F}$ & Export & & & \\
\hline B 1 & \multicolumn{2}{|l|}{ Motor vehicle production } & G & \multicolumn{3}{|c|}{ Import YTD } & \\
\hline \multirow[t]{2}{*}{ C } & \multirow{2}{*}{\multicolumn{2}{|c|}{$\begin{array}{l}\text { Consumer confidence index } \\
\text { - current economic condition }\end{array}$}} & $\mathrm{H}$ & \multicolumn{3}{|c|}{ Total credit } & \\
\hline & & & I & \multicolumn{3}{|c|}{ Investment lending rate } & \\
\hline \multirow{2}{*}{$\frac{D}{E}$} & Industrial production index & & J & \multicolumn{3}{|l|}{ M1 } & \\
\hline & Electricity consumption & & K & Rupiah & te $(\mathrm{NE}$ & & \\
\hline
\end{tabular}


Nonetheless, the results of the exercise presented in Table 4.8 also demonstrate that the difference in performance amongst the 10 best indicator combinations was almost negligible, evidenced by the small difference in RMSE. Departing from the findings of the nowcasting exercise for household consumption, however, the RMSE of the investment nowcasting model was comparatively high at 1 . The authors expect that this was linked to fluctuating investment data (in yearon-year growth). When nowcasting investment, the indicators of cement sales, motor vehicle production and electric consumption were nearly always selected as components of the best combination.

Table 9 presents the results of nowcasting investment with the model selected for 2015, with an RMSE value of 1.03 and MAPE of 15\% (based on the evaluation in the third month). Nowcasting was performed for each quarter of 2015 and the exercise showed that the nowcasting model was more robust in the second month. In the third month, however, the results of the nowcasting exercise improved in the first and second quarters but actually deteriorated in the third and fourth quarters. Furthermore, a tendency to overshoot was also found when nowcasting the first and second quarters, contrasting the propensity to undershoot in the third and fourth quarters. The model was, however, the best one that could be produced. The proclivity to over- and undershoot must be taken into consideration when using the model in order to minimise the error or deviation.

Table 9.

Nowcasting with Selected Model - Investment

\begin{tabular}{ccccccccc}
\hline \multirow{2}{*}{ Period } & \multirow{2}{*}{ Realization } & \multicolumn{3}{c}{ Nowcasting Result [and Error/Deviation] } \\
\cline { 4 - 9 } & & \multicolumn{2}{c}{$\mathbf{1}^{\text {st }}$ month } & \multicolumn{2}{c}{$\mathbf{2}^{\text {nd }}$ month } & \multicolumn{2}{c}{$3^{\text {rd }}$ month } \\
\hline \multirow{3}{*}{2015} & I & 4.63 & 5.45 & 0.82 & 5.19 & 0.56 & 5.11 & 0.48 \\
& II & 3.88 & 5.24 & 1.36 & 4.85 & 0.97 & 4.63 & 0.75 \\
& III & 4.79 & 4.33 & $(0.46)$ & 4.64 & $(0.15)$ & 4.60 & $(0.19)$ \\
& IV & 6.90 & 5.34 & $(1.56)$ & 5.28 & $(1.62)$ & 5.06 & $(1.84)$ \\
\hline
\end{tabular}

Table 10 presents the results of nowcasting investment in Q3-2015 using the latest data to represent actual conditions. In the first month, the deviation was observed to remain at 0.46 in line with the inclusion of total credit and M1. The deviation subsequently dropped significantly in the second month with the inclusion of the latest motor vehicle sales data. Nevertheless, inclusion of the latest cement sales, motor vehicle production and electricity consumption data actually undermined the quality of the nowcasting results, while inclusion of total credit and M1 data significantly improved the nowcasting results. 
Table 10.

Nowcasting Result Based on Data Flow (Q3-2015) - Investment

\begin{tabular}{|c|c|c|c|c|c|}
\hline \multicolumn{2}{|c|}{ Period } & \multirow[b]{2}{*}{ Data Release } & \multirow{2}{*}{\multicolumn{2}{|c|}{$\begin{array}{c}\text { Nowcasting Result } \\
\text { [and Error/ } \\
\text { Deviation] }\end{array}$}} & \multirow[b]{2}{*}{ Realization } \\
\hline Month & Week & & & & \\
\hline \multirow{5}{*}{$1^{\text {st }}$ month } & & & & & \multirow{16}{*}{4.79} \\
\hline & 2 & Cement sales & 4.33 & $(0.46)$ & \\
\hline & & $\begin{array}{l}\text { Motor vehicle production } \\
\text { Electricity consumption }\end{array}$ & & & \\
\hline & 3 & -- & 4.33 & $(0.46)$ & \\
\hline & 4 & $\begin{array}{l}\text { Total credit } \\
\text { M1 }\end{array}$ & 4.33 & $(0.46)$ & \\
\hline \multirow{6}{*}{$2^{\text {nd }}$ month } & 1 & -- & 4.33 & $(0.46)$ & \\
\hline & 2 & Cement sales & 4.63 & $(0.16)$ & \\
\hline & & Motor vehicle production & & & \\
\hline & & Electricity consumption & & & \\
\hline & 3 & -- & 4.63 & $(0.16)$ & \\
\hline & 4 & $\begin{array}{l}\text { Total credit } \\
\text { M1 }\end{array}$ & 4.64 & $(0.15)$ & \\
\hline \multirow{5}{*}{$3^{\text {rd }}$ month } & 1 & -- & 4.64 & $(0.15)$ & \\
\hline & 2 & Cement sales & 4.55 & $(0.24)$ & \\
\hline & & $\begin{array}{l}\text { Motor vehicle production } \\
\text { Electricity consumption }\end{array}$ & & & \\
\hline & 3 & -- & 4.55 & $(0.24)$ & \\
\hline & 4 & $\begin{array}{l}\text { Total credit } \\
\text { M1 }\end{array}$ & 4.60 & $(0.19)$ & \\
\hline
\end{tabular}

\subsection{Model Performance Evaluation}

As mentioned previously, model performance was evaluated by comparing the nowcasting results to the benchmark models, in this case the Bridge Equation and ARIMA model. As presented in Table 11, the comparison of model accuracy for nowcasting household consumption showed that the forecast error of the Dynamic Factor Model was smaller than the forecasting error of the Bridge Equation and

Table 11.

Comparison with Other Models - Household Consumption

\begin{tabular}{ccccccccc}
\hline \multirow{2}{*}{ Nowcasting } & & \multicolumn{3}{c}{ Nowcasting Result [and Error/ Deviation] } \\
\cline { 3 - 9 } & Realization & \multicolumn{2}{c}{$\begin{array}{c}\text { Dynamic Factor } \\
\text { Model }\end{array}$} & Bridge Equation & ARIMA \\
\hline \multirow{2}{*}{2015} & I & 5.01 & 5.00 & $(0.01)$ & 4.33 & $(0.68)$ & 4.98 & $(0.03)$ \\
& II & 4.97 & 4.99 & 0.03 & 4.64 & $(0.33)$ & 4.90 & $(0.06)$ \\
& III & 4.95 & 4.96 & 0.01 & 4.50 & $(0.45)$ & 4.88 & $(0.07)$ \\
& IV & 4.92 & 4.94 & 0.01 & 4.43 & $(0.50)$ & 4.87 & $(0.06)$ \\
\hline
\end{tabular}


ARIMA. Therefore, nowcasting household consumption using the DFM model was shown to be the most robust.

On the other hand, the comparison of model accuracy for nowcasting investment showed that the forecast error of the Dynamic Factor Model was smaller than the forecasting error of the Bridge Equation and ARIMA, as presented in Table 4.12. The forecast error of the DFM model was considered significant but smaller than that of the benchmark models.

Table 12.

Comparison with Other Models - Investment

\begin{tabular}{ccccccccc}
\hline \multirow{2}{*}{ Nowcasting } & & \multicolumn{3}{c}{ Nowcasting Result [and Error/ Deviation] } \\
\cline { 3 - 8 } & Realization & \multicolumn{2}{c}{$\begin{array}{c}\text { Dynamic Factor } \\
\text { Model }\end{array}$} & Bridge Equation & ARIMA \\
\hline \multirow{2}{*}{2015} & I & 4.63 & 5.06 & 0.48 & 3.10 & $(1.53)$ & 5.38 & 0.75 \\
& II & 3.88 & 4.73 & 0.75 & 3.97 & 0.09 & 5.43 & 1.55 \\
& III & 4.79 & 4.63 & $(0.19)$ & 4.00 & $(0.79)$ & 4.78 & $(0.01)$ \\
& IV & 6.90 & 5.06 & $(1.84)$ & 4.31 & $(2.59)$ & 5.68 & $(1.22)$ \\
\hline
\end{tabular}

\section{CONCLUSION}

\subsection{Conclusion}

A number of conclusions can be drawn from the research as follows:

1. The most robust nowcasting models for household consumption and investment were built using the Dynamic Factor Model (DFM) method based on the various testing and exercise stages. The indicators used for nowcasting household consumption were motor vehicle sales, total deposit, consumer lending rate, M1, and the Rupiah exchange rate (NEER), while the indicators used for nowcasting investment included cement sales, motor vehicle production, electricity consumption, total credit, and M1.

2. Accuracy testing revealed that the forecast error of the household consumption nowcasting model using the DFM method was small and, therefore, robust in terms of predicting the level of household consumption. Meanwhile, the forecast error of the investment nowcasting model using the DFM method was large enough but smaller than the benchmark models (Bridge Equation and ARIMA).

\subsection{Recommendations}

The recommendations of the research are as follows:

1. Before the nowcasting models for household consumption and investment can formally be applied to FPAS, further testing is required to observe the accuracy of the nowcasting models for the first two quarters of 2016.

2. Nowcasting models for the other components of GDP should be developed to ensure Bank Indonesia has accurate nowcasting models for all components of GDP. 


\section{REFERENCE}

Andersson, Michael K. and Reijer, J.J. den. (2015). Nowcasting. Sveriges Riksbank Economic Review, No. 2015:1.

Andreou, Elena; Ghysels, Eric; and Kourtellos, Andros. (2010). Regression Models with Mixed Sampling Frequencies. Journal of Econometrics, 158.

Angelini, Elena; Camba-Méndez, Gonzalo; Giannone, Domenico; Rünstler, Gerhard; and Reichlin, Lucrezia. (2008). Short-Term Forecasts of Euro Area GDP Growth.ECB Working Paper Series, No. 949.

Aruoba, S. Boragan; Diebold, Francis X.; and Scotti, Chiara. "Real-Time Measurement of Business Conditions. (2012).Journal of Business and Economic Statistics, No. 27:4.

Baffigi, Alberto; Golinelli, Roberto; and Parigi, Giuseppe. (2004). Bridge Models to Forecast the Euro Area GDP. International Journal of Forecasting, 20.

Bańbura, Marta and Rünstler, Gerhard. (2011). A Look into the Factor Model Black Box: Publication Lags and the Role of Hard and Soft Data in Forecasting GDP. International Journal of Forecasting, 27.

Bańbura, Marta; Giannone, Domenico; and Reichlin, Lucrezia. (2011). Nowcasting. The Oxford Handbook of Economic Forecasting.

Bańbura, Marta; Giannone, Domenico; Modugno, Michele; and Reichlin, Lucrezia. (2012). Now-Casting and the Real-Time Data Flow.ECARES Working Paper, No. 2012-026.

Bell, Venetia; Co, Lai Wah; Stone, Sophie; and Wallis, Gavin. (2014). Nowcasting UK GDP Growth. Bank of England Quarterly Bulletin Q1-2014.

Burns, Arthur F. and Mitchell, Wesley C. Measuring Business Cycles. (1946). New York: NBER.

Camacho, Maximo and Perez-Quiros, Gabriel. (2010). Introducing the Euro-Sting: Short-Term Indicator of Euro Area Growth. Journal of Applied Econometrics, 25(4).

Diebold, Francis X. and Rudebusch, Glenn D. (1996). Measuring Business Cycles: A Modern Perspective. The Review of Economics and Statistics, 78(1).

Doz, Catherine; Giannone, Domenico; and Reichlin, Lucrezia. (2011). A Two-Step Estimator for Large Approximate Dynamic Factor Models Based on Kalman Filtering. Journal of Econometrics, 164.

Foroni, Claudia and Marcellino, Massimiliano. (2013). A Survey of Econometric Methods for Mixed-Frequency Data. Norges Bank Research Working Paper, No. 2013/06.

Ghysels, Eric; Santa-Clara, Pedro; and Valkanov, Rossen. (2004). The MIDAS Touch: Mixed Data Sampling Regression Models.

Giannone, Domenico; Reichlin, Lucrezia; and Small, David. (2008). Nowcasting: The Real-Time Informational Content of Macroeconomic Data.Journal of Monetary Economics, 55.

Hamilton, James D. (1994). State-Space Models in Engle, R.F. and McFadden, D.L. Handbook of Econometrics. Elsevier Science B.V.

Kurniawan, Ferry. (2015). Nowcasting Indonesian Economy. Jakarta: Bank Indonesia.

Luciani, Matteo; Pundit, Madhavi; Ramayandi, Arief; and Veronese, Giovanni. (2015). Nowcasting Indonesia. FRB Finance and Economics Discussion Series, No. 2015-100. 
Mariano, Roberto S. and Murasawa, Yasutomo. (2003). A New Coincident Index of Business Cycles Based on Monthly and Quarterly Series. Journal of Applied Econometrics, 18(4).

Mariano, Roberto S. and Murasawa, Yasutomo. (2010). A Coincident Index, Common Factors, and Monthly Real GDP.Oxford Bulletin of Economics and Statistics, 72(1).

OECD System of Composite Leading Indicators. (2012). OECD.

Schorfheide, Frank and Song, Dongho. (2013). Real-Time Forecasting with a Mixed-Frequency VAR. NBER Working Paper Series, No. 19712.

Sørensen, Jonas. (2011). Indicator Models for Private Consumption.Monetary Review, ${ }^{\text {st }}$ Quarter 2011.

Stock, James H. and Watson, Mark W. (1989). New Indexes of Coincident and Leading Economic Indicators. Blanchard, Olivier Jean dan Fischer, Stanley (Eds.). NBER Macroeconomics Annual 1989, Volume 4.

The Conference Board. Business Cycle Indicators Handbook. (2001). 
This page is intentionally left blank 